\title{
Dynamic ion speciation during hydrolysis of aryltrifluoroborates
}

\author{
Isaac Omari, Lars P. E. Yunker, Johanne Penafiel, Darlene Gitaari, Atzin San Roman, J. Scott \\ McIndoe* \\ Department of Chemistry, University of Victoria, P.O. Box 3065 Victoria, BC V8W3V6, \\ Canada. \\ Fax: +1 (250) 721-7147; Tel: +1 (250) 721-7181; E-mail: mcindoe@uvic.ca
}

\begin{abstract}
Organotrifluoroborates serve as a coupling partner during transmetallation in the Suzuki-Miyaura reaction but require hydrolysis prior to the coupling reaction. Their anionic nature allows study of their hydrolysis by electrospray ionization mass spectrometry (ESI-MS) by real-time monitoring, complemented by $\mathrm{pH}$ analysis. Induction periods varied according to the borates employed, and a dynamic series of equilibria for numerous ions was observed during hydrolysis. We found that the induction periods and reaction rates were sensitive to the $\mathrm{R}$ group of the borates, the shape of reaction vessel, and stir rate, and that after complete decay of all of the aryltrifluoroborate ion the solution contained a variety of partially hydrolyzed species.
\end{abstract}




\section{Graphical abstract}

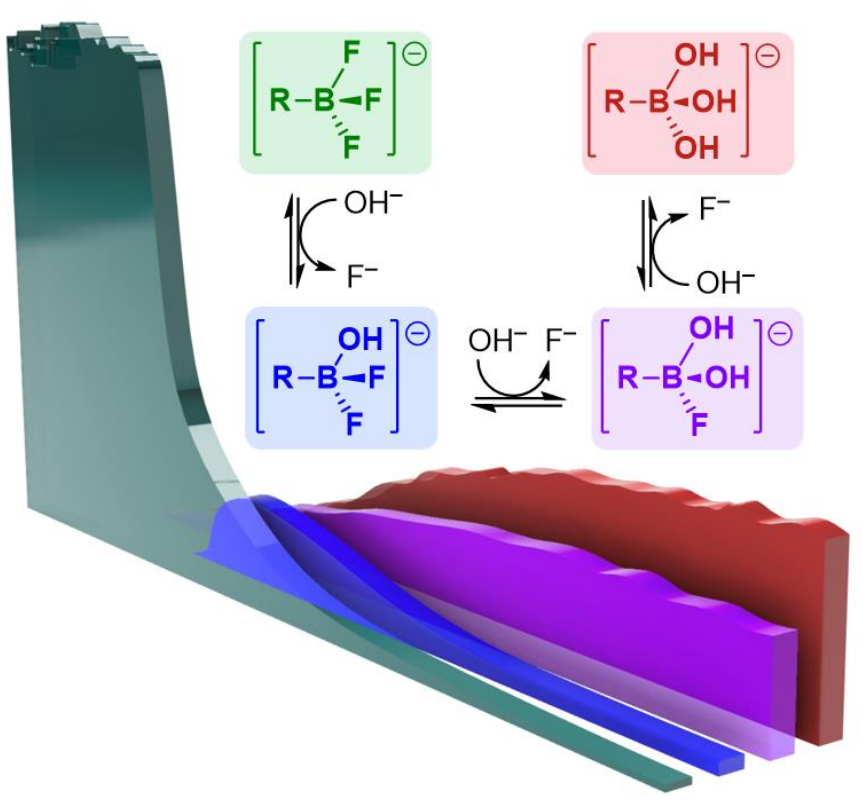




\section{Introduction}

Many organoboronic acids are known to be inherently unstable to oxidation or protolytic deboronation; making their benchtop handling and storage difficult. ${ }^{1,2}$ As an alternative, chemists sometimes use stable, easy to handle organoborate salts. As such, organotrifluoroborates, along with N-methyliminodiacetic acid (MIDA) boronates, ${ }^{3-6}$ have become common organoboron sources in the Suzuki-Miyaura reaction..$^{7-16}$ They require hydrolysis ${ }^{17-19}$ prior to the coupling reaction and the Lloyd-Jones research group has extensively studied this hydrolysis reaction by nuclear magnetic resonance (NMR). ${ }^{20-22}$ They proposed that in THF-water mixtures, a biphasic system with three mechanisms of hydrolysis is at work (Scheme 1). The hydrolysis is catalyzed in path $\mathrm{A}$ by acid and is correspondingly retarded by base ${ }^{20}$ Fluoride dissociation by path B is accelerated by base, and a third path $\mathrm{C}$ is active in the aqueous phase for hydrophilic substituents and is accelerated by base. ${ }^{20}$ They noticed that upon addition of water, the mixture needed to reach a critical $\mathrm{pH}$ (induction period) for the reaction to start through path A but were unable to observe any intermediate species between $\mathrm{RBF}_{2}$ and $\mathrm{RB}(\mathrm{OH})_{2}(\mathrm{R}=\mathrm{Ak}, \mathrm{Ar}){ }^{20}$ Considering that organotrifluoroborates are anionic, we were interested to see whether we could observe the dynamics of any of these ions (i.e. $\left.\left[\mathrm{RBF}_{n}(\mathrm{OH})_{3-n}\right]^{-}, n=0-3\right)$ by methods developed in our laboratory, namely pressurized sample infusion (PSI) coupled with electrospray ionization mass spectrometry (ESI-MS). ${ }^{23,24}$ This sample introduction method enables real-time analysis of a complex reacting solution. ${ }^{25-28}$ In addition, changes in $\mathrm{pH}$ due to speciation during hydrolysis could be measured in parallel using a $\mathrm{pH}$ meter. 


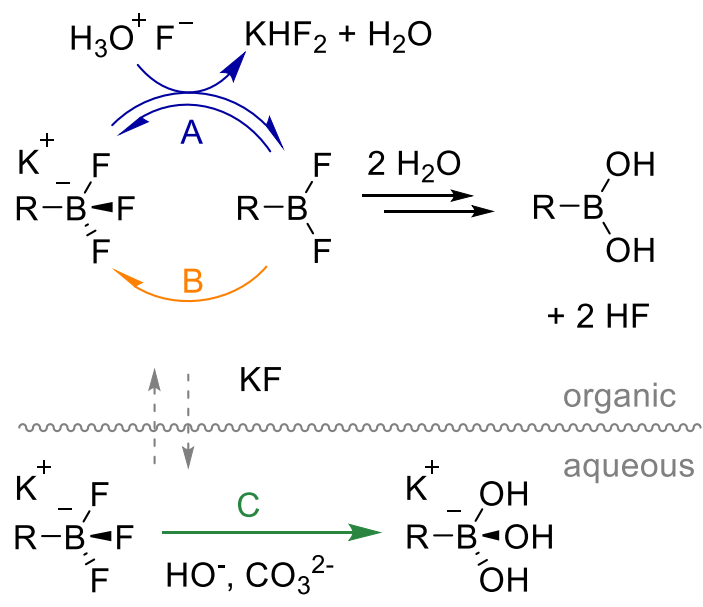

Scheme 1: Trifluoroborate hydrolysis pathways proposed by Lloyd-Jones and Perrin $(R=$ alkyl, aryl).20,29

\section{Experimental}

Reagents were purchased from Sigma-Aldrich and were used without further purification. Gases used were purchased from Airgas. Tetrahydrofuran was distilled over $\mathrm{CaH}_{2}$ and stored under an inert atmosphere prior to use. The instrument used for all monitored reactions was a Waters Acquity Triple Quadrupole Detector. ESI source parameters were as follows: capillary voltage was held at $3 \mathrm{kV}$, cone voltage at $12.0 \mathrm{~V}$, and extraction cone at $1 \mathrm{~V}$. The following settings were used to obtain optimal desolvation conditions: desolvation gas flow rate $200 \mathrm{~L} / \mathrm{hr}$, cone gas flow rate $100 \mathrm{~L} / \mathrm{hr}$, source temperature $100^{\circ} \mathrm{C}$, desolvation temperature $180^{\circ} \mathrm{C}$. The detector gain was set to an optimal voltage of $470 \mathrm{~V}$. Scan time was set to $1 \mathrm{~s}$, with an inter-scan time of $0.1 \mathrm{~s}$. The collision gas flow (high purity argon) was switched off except in tandem mass spectrometric experiments (MS/MS). MS/MS experiments were conducted with a collision energy between 2$15 \mathrm{~V}$. IKA RCT B hot plate magnetic stirrer was used for all experiments. The $\mathrm{pH}$ measurements were recorded with an HI 2020-01 pH meter equipped with HI 10430 digital pH electrode.

A typical reaction for trifluoroborate hydrolysis is as follows. A PSI-ESI(-)-MS setup was prepared under an inert atmosphere with a potassium trifluoroborate salt $(12 \mu \mathrm{mol}, 1 \mathrm{eq})$ in tetrahydrofuran in a Schlenk tube and a round-bottom style flask. The reaction mixture temperature was raised to $55^{\circ} \mathrm{C}$, stirring rate was set identically to all other experiments $(\sim 168$ $\mathrm{rpm}$ and $\sim 600 \mathrm{rpm}$ for slow and fast stir rate experiments respectively). The reaction mixture was 
connected to the ESI source by a piece of FEP tubing, and acquisition was initiated. Cesium carbonate $(36 \mu \mathrm{mol}, 3 \mathrm{eq})$ was dissolved in distilled water and injected into the reaction mixture. Reactions were carried out for potassium salts of $\mathrm{p}$-tolyltrifluoroborate $\left(\mathrm{p}-\mathrm{MeC}_{6} \mathrm{H}_{4} \mathrm{BF}\right.$ ), $\mathrm{p}-$ methoxyphenyltrifluoroborate ( $\left.\mathrm{p}-\mathrm{MeOC}_{6} \mathrm{H}_{4} \mathrm{BF}_{3}\right)$, and cyclohexyltrifluoroborate $\left(\mathrm{CyBF}_{3}\right)$. Realtime $\mathrm{pH}$ experiments were also carried out separately following the same procedure as described for the ESI-MS experiments. Methodological optimization and careful experimental technique were required to obtain reliable equilibrium behaviour between reactions, but the observed hydrolysis species were consistent between reactions and across substrates.

\section{Results and Discussion}

We settled on investigating three organotrifluoroborate potassium salts: p-tolyltrifluoroborate, $\mathrm{p}$ methoxyphenyltrifluoroborate, and cyclohexyltrifluoroborate. These were shown by Perrin ${ }^{29}$ and Lloyd-Jones ${ }^{20}$ to be the fastest hydrolyzing examples, and therefore were the best match for our methodology (PSI-ESI-MS gathers spectra on a timescale of seconds, so dense data can be collected in minutes). The hydrolysis was studied with a 1:3 ratio of organotrifluoroborate to base $\left(\mathrm{Cs}_{2} \mathrm{CO}_{3}\right)$ and a $\mathrm{THF} / \mathrm{H}_{2} \mathrm{O}$ ratio of 10:1. In order to avoid saturation issues in our mass spectrometer, concentration of the borate was kept at $1.8 \mathrm{mM}$. We examined the reaction at slow $(\sim 168 \mathrm{rpm})$ and fast $(\sim 600 \mathrm{rpm})$ stir rates, and in both a round-bottomed flask and in a Schlenk tube. Reactions were also monitored separately using a $\mathrm{pH}$ meter.

The anionic speciation profile of the reaction mixture prior to addition of base and water was simple, showing signals only for $\left[\mathrm{ArBF}_{3}\right]^{-}$and its corresponding aggregate ion $\left[\left(\mathrm{ArBF}_{3}\right)_{2} \mathrm{~K}\right]^{-}$(Figure 1A). Addition of base and water soon resulted in a profusion of new peaks (Figure 1B). These peaks could be assigned to partially hydrolyzed, dehydrated, and aggregate ions. 

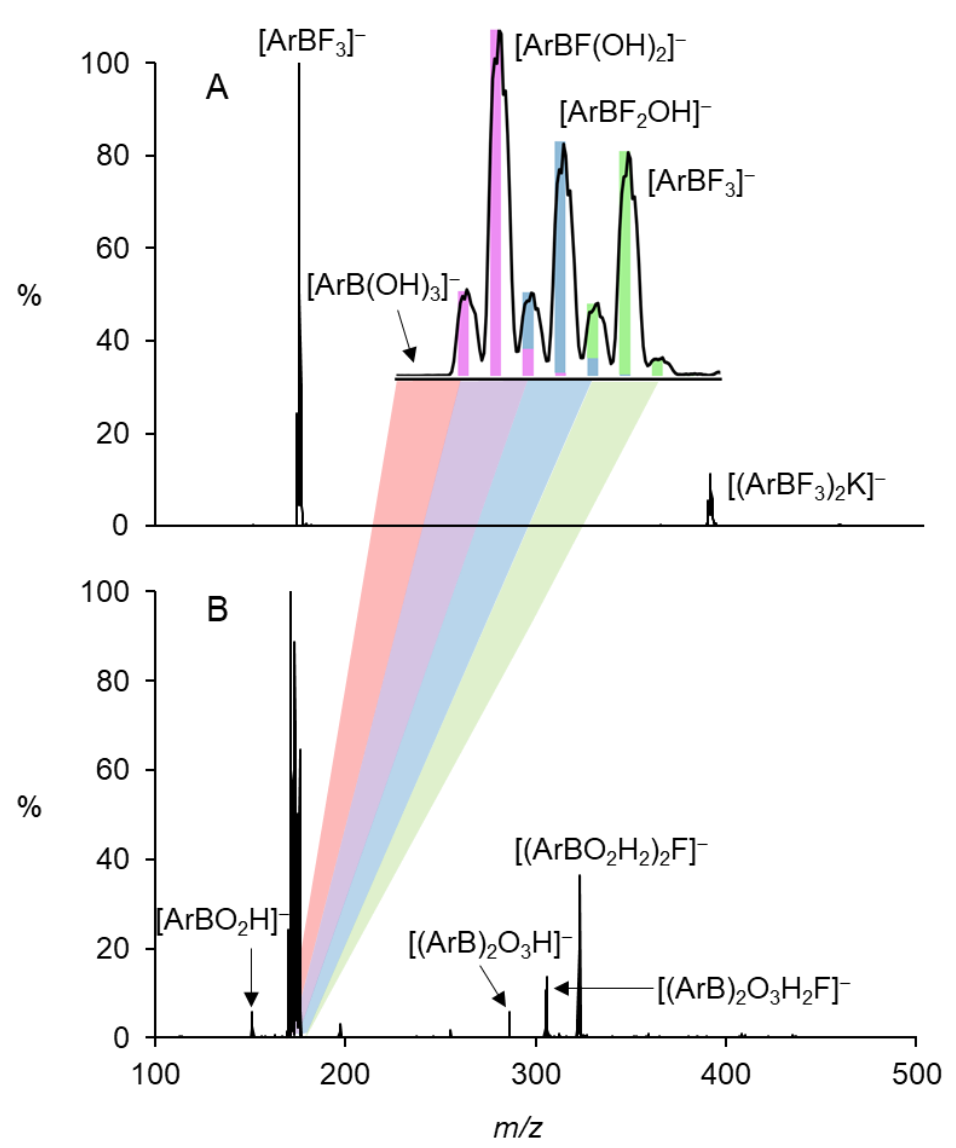

Figure 1: (A) negative ion mass spectrum of $\mathrm{KArBF}_{3}$ in THF. (B) negative ion mass spectrum of the same solution, 20 minutes after addition of water and $\mathrm{Cs}_{2} \mathrm{CO}_{3}$. Inset: magnification of the $\left[\operatorname{ArBF}_{n}(\mathrm{OH})_{3-n}\right]^{-}(n=0-$ 3 ) region of the spectrum at $t=20$ minutes.

We expected to observe each progressive species in the conversion from $\left[\mathrm{RBF}_{3}\right]^{-}(\mathbf{1})$ through to $\left[\mathrm{RB}(\mathrm{OH})_{3}\right]^{-}$(7) (Scheme 2), but the equilibria are more complex than we had first guessed. We observed aggregates, such as $\left[\left(\mathrm{RBF}_{3}\right)_{2} \mathrm{M}\right]^{-}(\mathrm{M}=\mathrm{K}$ or $\mathrm{Cs})$, dehydrated species, such as $\left[\mathrm{RBO}_{2} \mathrm{H}\right]^{-}(\mathbf{8})$ and $\left[\mathrm{R}_{2} \mathrm{~B}_{2} \mathrm{O}_{3} \mathrm{H}\right]^{-}(\mathbf{9})$; and mixed dimers, such as $\left[\mathrm{R}_{2} \mathrm{~B}_{2} \mathrm{O}_{3} \mathrm{H}_{2} \mathrm{~F}\right]^{-}(\mathbf{1 0})$. Given that dehydrated boronic acids are known to adopt cyclic structures, ${ }^{30-33}$ we assigned a hydrogen-bond stabilized boroxine-type structure for 9 . 


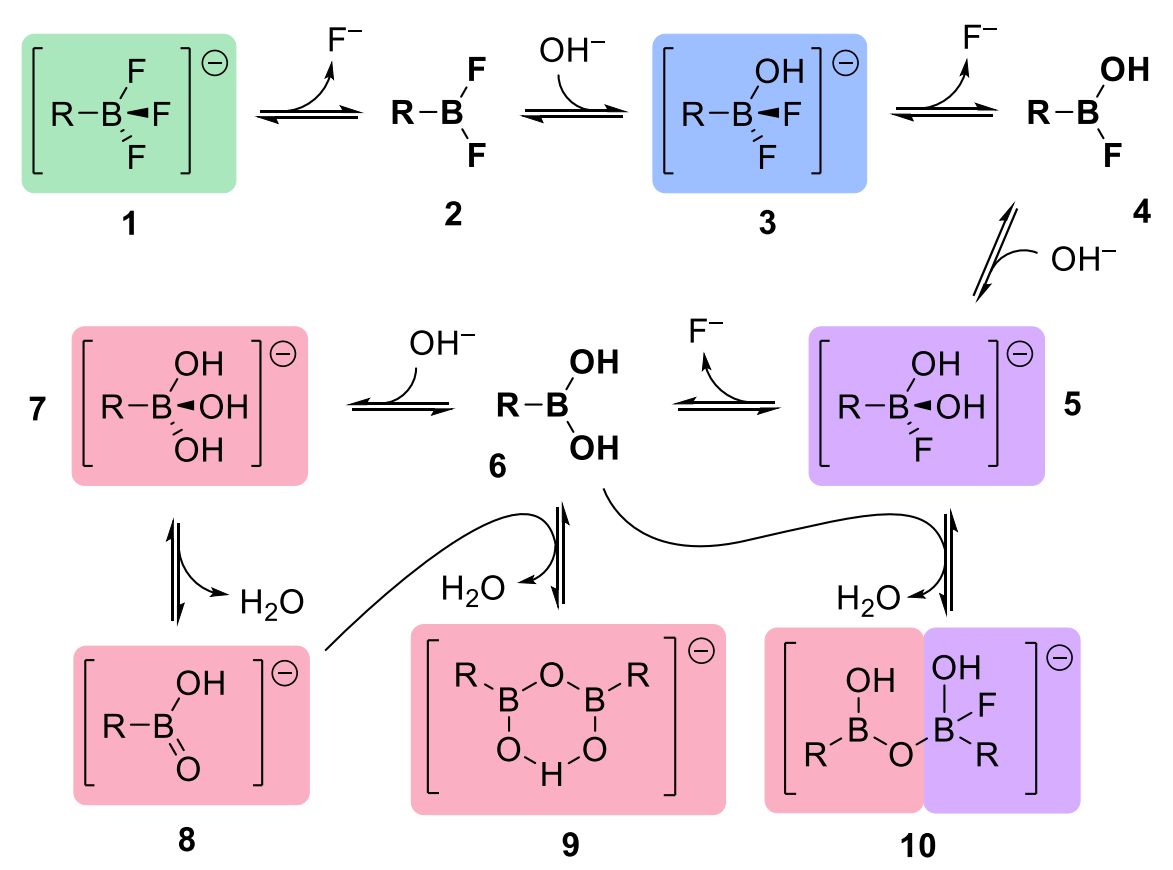

Scheme 2: Proposed equilibria for trifluoroborate hydrolysis. Highlighted species are ionic and observable by ESI-MS. Structural connectivity is proposed based on structures of these molecular formulae in the literature. ${ }^{34}$

Species $\mathbf{8}$ is of relevance for a Suzuki-Miyaura reaction, as it is structurally part of a pretransmetallation intermediate proposed by Denmark. ${ }^{34,35}$ For more electron withdrawing groups ${ }^{29}$ such as for 4-methoxyphenyltrifluoroborate or $p$-tolyltrifluoroborate, the formation of $\mathbf{8}$ will be more favored than for the cyclohexyltrifluoroborate salt hydrolysis. We found that the ratio of intensities for ions 7:8 varied for each different $\mathrm{R}$ group of the borates in all reactions, and also varied with $\mathrm{pH}$ (see supporting information). No species corresponding to $\left[\mathrm{KF}_{2}\right]^{-}$, $\left[\mathrm{CsF}_{2}\right]^{-},\left[\mathrm{BF}_{4}\right]^{-}$, nor $\left[\mathrm{B}(\mathrm{OH})_{4}\right]^{-}$were observed. $\left[\mathrm{KF}_{2}\right]^{-}$and $\left[\mathrm{CsF}_{2}\right]^{-}$are byproducts of path $\mathrm{A},{ }^{20}$ and $\left[\mathrm{BF}_{4}\right]^{-}$and $\left[\mathrm{B}(\mathrm{OH})_{4}\right]^{-}$are protodeboronation byproducts. ${ }^{36}$

All numbered species exhibited dynamic behaviour and could be classified into different types according to their degree of hydrolysis. All species related to each $\left[\operatorname{ArBF}_{3-\mathrm{n}}(\mathrm{OH})_{n}\right]^{-}(n=0-3$, i.e., $1,3,5$ and 7 respectively) through aggregation or dehydration were grouped together for the sake of simplicity of interpretation. Since different ions provide different ESI-MS response, ${ }^{37}$ and neutrals are not detected at all (unless associated with a charged entity), traces of species in this study do not directly correspond to concentrations. Rather, they indicate the approximate 
proportion of the charged components of a mixture that can be attributed to a particular ion (or group of related ions). A composite presentation of a representative data set is shown in Figure 2, for the hydrolysis of potassium p-methoxyphenyltrifluoroborate in a Schlenk tube at a slow stir rate.

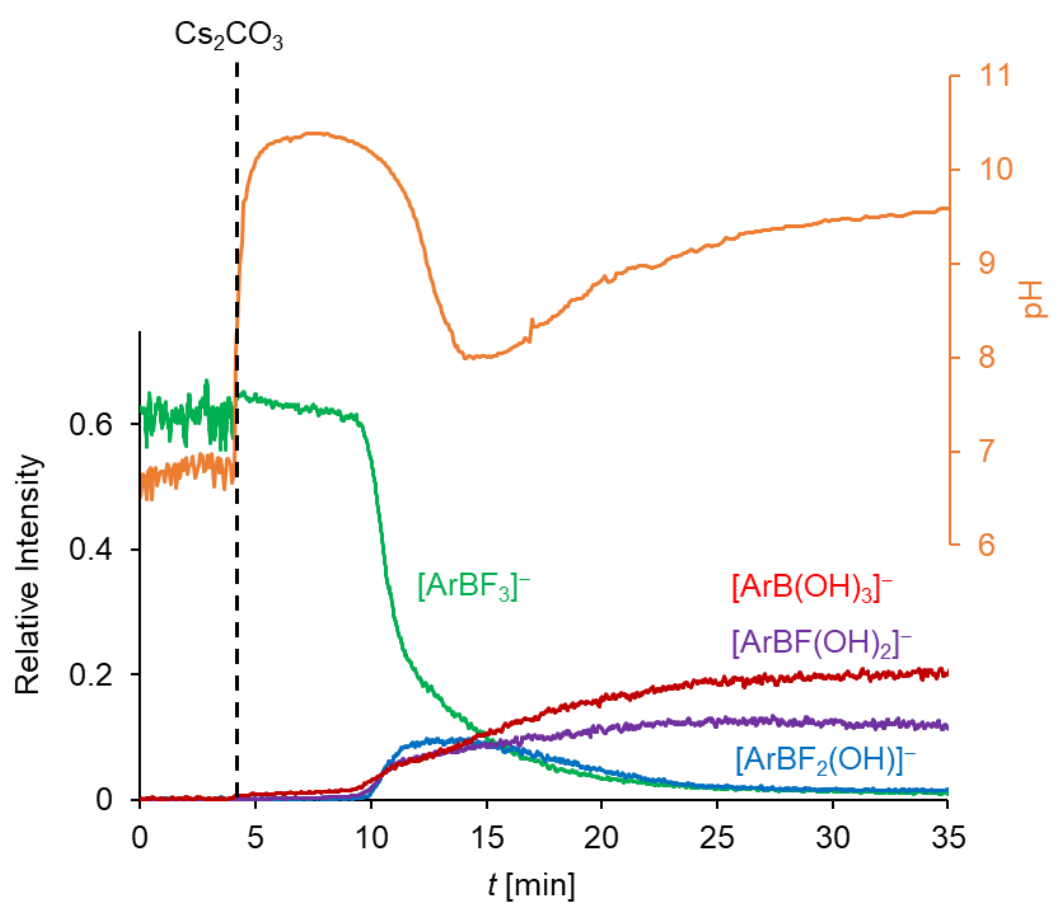

Figure 2: Relative species intensity and $\mathrm{pH}$ values for the hydrolysis of potassium p-methoxyphenyltrifluoroborate in THF $\left(55^{\circ} \mathrm{C}\right)$ performed in a Schlenk tube style at a slow stir rate. $\mathrm{Cs}_{2} \mathrm{CO}_{3}$ in $\mathrm{H}_{2} \mathrm{O}$ was added at 4 minutes. The $\left[\mathrm{ArB}(\mathrm{OH})_{3}\right]^{-}$trace is a sum of intensities of all species with $\mathrm{F}$ $=0$, i.e. $\mathbf{7}+\mathbf{8}+\mathbf{9}+1 / 2 \mathbf{1 0}$.

In Figure 2, the combination of $\mathrm{pH}$ measurements with ESI-MS confirmed the relation between $\mathrm{pH}$ and the system's dynamics. Upon addition of a base to a THF solution of the trifluoroborates, the $\mathrm{pH}$ increased immediately from approximately 7 to 10 with a brief induction period which agreed with the ESI-MS result (Figure 2); however, other cases showed long induction periods under same reaction conditions (see supporting information). The end of the induction period was indicated by an abrupt $\mathrm{pH}$ drop for all substrates (Figure 2 and supporting information), possibly due to mopping up of HF by the base. ${ }^{20}$ After the $\mathrm{pH}$ drop, there was a slow $\mathrm{pH}$ recovery and expansion as shown in Figure 2 and supporting information. Although a base is necessary for hydrolysis, it also hinders full hydrolysis. This explains the increase in $\mathrm{pH}$ after the induction period. ${ }^{29}$ Parallel analysis with ESI-MS indicated in Figure 2 showed a first order decay in trifluoroborate at the end of the induction period (see supporting information) as well as 
evolution of hydrolyzed species which reached equilibrium with the substrate after 22 minutes of base addition. Further, the $\mathrm{pH}$ recovery seen in Figure 2 notably started where the trace of $\left[\mathrm{ArBF}_{3}\right]^{-}$crossed that of $\left[\mathrm{ArBF}_{2}(\mathrm{OH})\right]^{-}$. This probably indicates that the main contributor to the $\mathrm{pH}$ drop involves the consumption of $\left[\mathrm{ArBF}_{3}\right]^{-}$.

We also observed that different reaction vessels (Schlenk tube vs. round-bottomed flask) and changes in stirring rate could substantially affect the reaction rate. For example, in Figure 3, reactions conducted in a Schlenk tube mostly had relatively low rates of hydrolysis compared with a round-bottomed flask. Lloyd-Jones ${ }^{20}$ and Hartwig ${ }^{38}$ determined that, in a Schlenk tube better phase contact is achieved between the bulk solvent and the basic aqueous solution. The rate of base transfer into the bulk medium is comparatively increased in a Schlenk tube which could suppress hydrolysis ${ }^{20}$; but herein, hydrolysis of $\mathrm{K}\left[p-\mathrm{MeOC}_{6} \mathrm{H}_{4} \mathrm{BF}_{3}\right]$ and $\mathrm{K}\left[\mathrm{CyBF}_{3}\right]$ in a Schlenk tube at fast and slow stir rates respectively did not show any change in the rate of hydrolysis. In addition, changes in stirring rate affected the induction periods (see Figure 4 and supporting information). Figure 4a shows an example where hydrolysis of potassium ptolyltrifluoroborate at a fast stir rate never reached the catalytic regime; whereas at a slow stir rate (Figure $4 \mathrm{~b}$ ), a gradual conversion was observed with an induction time of approximately 10 minutes, followed by catalytic hydrolysis. With increased stir rates, Lloyd-Jones and co-workers found that the transfer of base from aqueous to organic phase is possibly facilitated which could retard acid catalytic activity by sequestering $\mathrm{HF}^{20}{ }^{20}$ However, in this study, we observed that the rates of hydrolysis for $\mathrm{K}\left[p-\mathrm{MeOC}_{6} \mathrm{H}_{4} \mathrm{BF}_{3}\right]$ and $\mathrm{K}\left[\mathrm{CyBF}_{3}\right]$ increased under fast stirring conditions which was unexpected (see Figure 3 and supporting information). This discrepancy with their findings could be attributed to differences in reaction vessels (PTFE $v s$. glass vessel in this study), stirring rate (100 rpm vs. $168 \mathrm{rpm}$ for slow stirring rate and $500 \mathrm{rpm} v s .600 \mathrm{rpm}$ for fast stirring rate), and the concentration of the reagents used ( $8 \mathrm{mM} v s .1 .8 \mathrm{mM}$ for the borates and $24 \mathrm{mM} v s .5 .5 \mathrm{mM}$ for the base). 


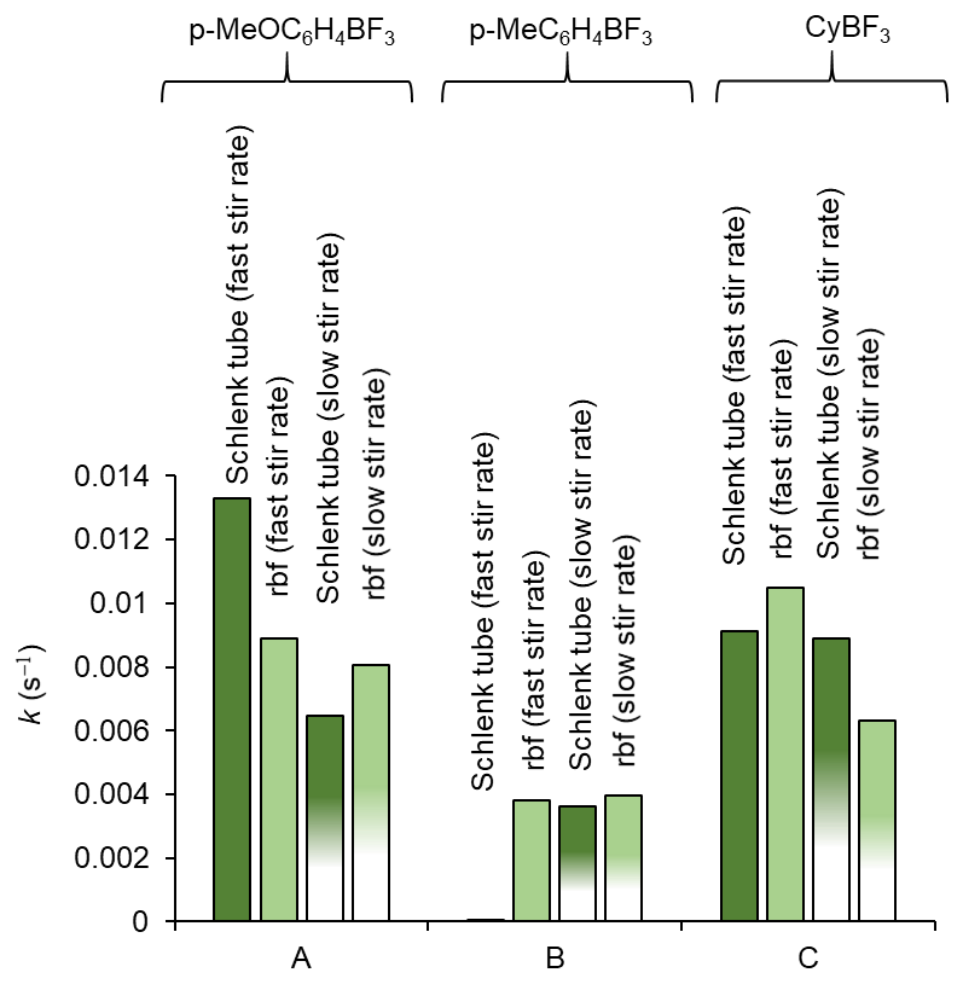

Figure 3: Representation of rate constants for the hydrolysis of potassium salts of $A$ ) $p$ -

methoxyphenyltrifluoroborate $\mathrm{B}) \mathrm{p}$-tolyltrifluoroborate $\mathrm{C}$ ) cyclohexyltrifluoroborate in $\mathrm{THF} / \mathrm{H}_{2} \mathrm{O}(10: 1)$ containing $\mathrm{Cs}_{2} \mathrm{CO}_{3}$; reaction was conducted in a Schlenk tube and round-bottomed flask at fast and slow stir rates. Rate constants were determined by linear regression of In(relative intensity) versus time (see supporting information). Fully shaded bars represent fast stir rate while the half-shaded bars represent slow stir rate.
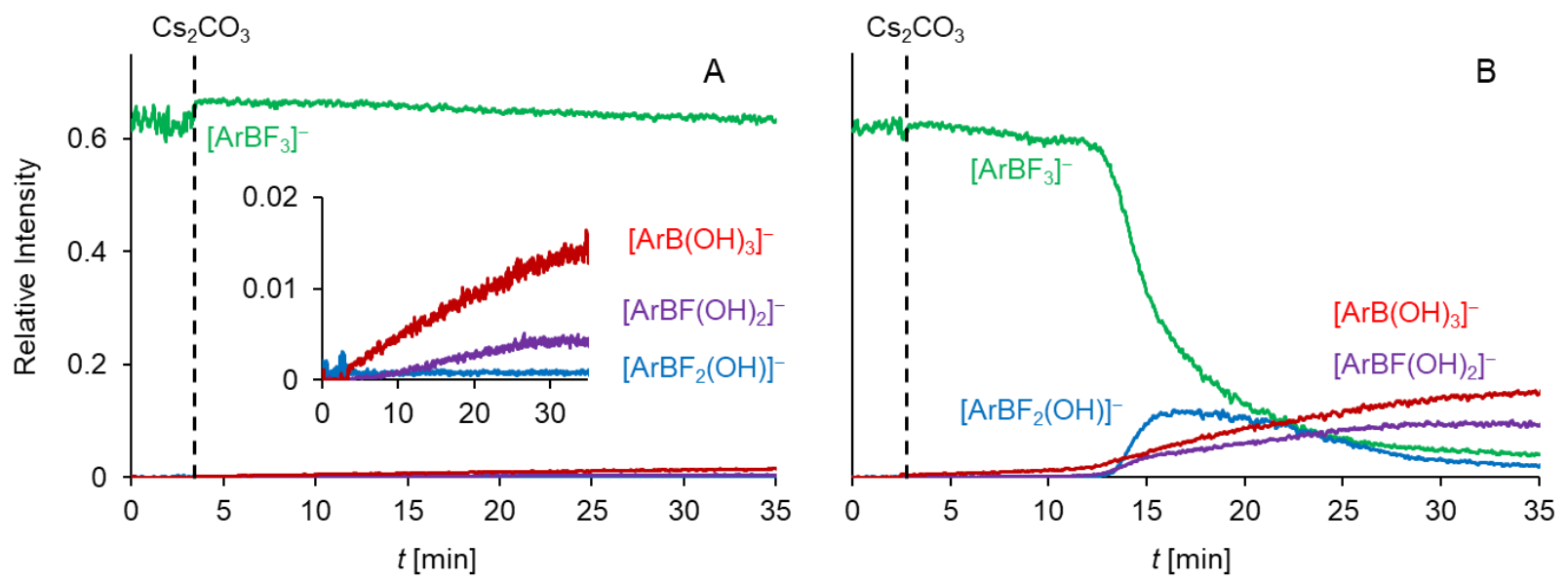

Figure 4: Relative species intensity for the hydrolysis of potassium p-tolyltrifluoroborate in $\mathrm{THF} / \mathrm{H}_{2} \mathrm{O}$ $(10: 1)$ containing $\mathrm{Cs}_{2} \mathrm{CO}_{3}$; performed at $(A)$ a fast stir rate, and $(B)$ a slow stir rate (see Figure $\mathrm{S} 5$, supporting information for duplicate chronogram). Inset in (A) represents hydrolyzed species; and the $\left[\mathrm{ArB}(\mathrm{OH})_{3}\right]^{-}$trace is a sum of intensities of all species with $\mathrm{F}=0$. 
As expected, the $\mathrm{R}$ group had a significant effect on the conversion rate of the trifluoroborates. As shown in Figure 3, the reaction rate for $p$-tolyltrifluoroborate was slower than that of $p$ methoxyphenyltrifluoroborate and cyclohexyltrifluoroborate; and as well, the induction period was relatively longer for the same substrate (see Figure 4a and supporting information). This implied that the tolyl group could stabilize the borate better than the $\mathrm{R}$ group of the other substrates, ${ }^{29}$ hence the order of reactivity was $p-\mathrm{MeOC}_{6} \mathrm{H}_{4} \mathrm{BF}_{3} \mathrm{~K} \sim \mathrm{CyBF}_{3} \mathrm{~K}>p-\mathrm{MeC}_{6} \mathrm{H}_{4} \mathrm{BF}_{3} \mathrm{~K}$. These results are consistent with previous studies.

\section{Conclusions}

Real time analysis of the hydrolysis of aryltrifluoroborates using ESI-MS confirms many of the behaviours previously revealed by ${ }^{19} \mathrm{~F}$ NMR, including sensitivity to stir rates and flask geometry and the existence of significant induction periods following the addition of base. ESI-MS reveals additional details: the presence of a complex soup of reaction products, including not just partially hydrolyzed products, but also dehydrated products and aggregate species thereof. The system eventually settles into a complex equilibrium in which a wide array of species is simultaneously present. This complex speciation points to an equally complex system when aryltrifluoroborates are used as an aryl source in Suzuki-Miyaura reactions; what might on paper seem to be a single-component addition may instead have a complicated effect on the catalytic system. The next step will be to consider how this complex mixture is perturbed by the introduction of cross-coupling partners and ultimately which components most readily undergo transmetallation.

\section{Acknowledgements}

JSM thanks the NSERC Discovery Grant Program for operational funding and CFI, BCKDF, and the University of Victoria for infrastructural support. 


\section{References}

1 D. G. Hall, in Boronic Acids, Wiley-VCH Verlag GmbH \& Co. KGaA, Weinheim, FRG., Weinheim, Germany, 2011, vol. 1, pp. 1-133.

2 H. Doucet, European J. Org. Chem., 2008, 2008, 2013-2030.

3 D. M. Knapp, E. P. Gillis and M. D. Burke, J. Am. Chem. Soc., 2009, 131, 6961-6963.

4 J. Li, A. S. Grillo and M. D. Burke, Acc. Chem. Res., 2015, 48, 2297-2307.

5 G. R. Dick, D. M. Knapp, E. P. Gillis and M. D. Burke, Org. Lett., 2010, 12, 2314-2317.

6 E. P. Gillis and M. D. Burke, Aldrichimica Acta, 2009, 42, 17-27.

7 G. A. Molander and L. Jean-Gérard, in Organic Reactions, John Wiley \& Sons, Inc., Hoboken, NJ, USA, 2012, vol. 79, pp. 1-316.

8 R. Cella, R. L. O. R. Cunha, A. E. S. Reis, D. C. Pimenta, C. F. Klitzke and H. A. Stefani, J. Org. Chem., 2006, 71, 244-250.

9 A. K. L. Yuen and C. A. Hutton, Tetrahedron Lett., 2005, 46, 7899-7903.

G. A. Molander and M. Ribagorda, J. Am. Chem. Soc., 2003, 125, 11148-11149.

X. Du, M. Suguro, K. Hirabayashi, A. Mori, T. Nishikata, N. Hagiwara, K. Kawata, T. Okeda, H. F. Wang, K. Fugami and M. Kosugi, Org. Lett., 2001, 3, 3313-3316.

S. W. Wright, D. L. Hageman and L. D. McClure, J. Org. Chem., 1994, 59, 6095-6097.

R. A. Batey and T. D. Quach, Tetrahedron Lett., 2001, 42, 9099-9103.

S. Darses and J. P. Genet, Chem. Rev., 2008, 108, 288-325.

H. A. Stefani, R. Cella and A. S. Vieira, Tetrahedron, 2007, 63, 3623-3658.

A. J. J. Lennox and G. C. Lloyd-Jones, Chem. Soc. Rev., 2014, 43, 412-443.

G. A. Molander and T. Ito, Org. Lett., 2001, 3, 393-396.

G. A. Molander and B. Biolatto, Org. Lett., 2002, 4, 1867-1870.

G. A. Molander and B. Biolatto, J. Org. Chem., 2003, 68, 4302-4314.

A. J. J. Lennox and G. C. Lloyd-Jones, J. Am. Chem. Soc., 2012, 134, 7431-7441.

A. J. J. Lennox and G. C. Lloyd-Jones, Isr. J. Chem., 2010, 50, 664-674.

M. Butters, J. N. Harvey, J. Jover, A. J. J. Lennox, G. C. Lloyd-Jones and P. M. Murray, Angew. Chemie Int. Ed., 2010, 49, 5156-5160.

23 K. L. Vikse, Z. Ahmadi, J. Luo, N. Van Der Wal, K. Daze, N. Taylor and J. S. Mclndoe, Int. J. Mass Spectrom., 2012, 323-324, 8-13.

24 L. P. E. Yunker, R. L. Stoddard and J. S. Mclndoe, J. Mass Spectrom., 2014, 49, 1-8.

25 R. Theron, Y. Wu, L. P. E. Yunker, A. V. Hesketh, I. Pernik, A. S. Weller and J. S. McIndoe, ACS Catal., 2016, 6, 6911-6917.

26 E. Janusson, H. S. Zijlstra, P. P. T. Nguyen, L. Macgillivray, J. Martelino and J. S. Mclndoe, Chem. Commun., 2017, 53, 854-856.

27 U. Gellrich, A. Meißner, A. Steffani, M. Kähny, H. J. Drexler, D. Heller, D. A. Plattner and B. Breit, J. Am. Chem. Soc., 2014, 136, 1097-1104.

28 C. Vicent and D. G. Gusev, ACS Catal., 2016, 6, 3301-3309.

29 R. Ting, C. W. Harwig, J. Lo, Y. Li, M. J. Adam, T. J. Ruth and D. M. Perrin, J. Org. Chem., 2008, 73, 4662-4670.

30 S. J. Rettig and J. Trotter, Can. J. Chem., 1977, 55, 3071-3075.

31 H. R. Snyder, J. A. Kuck and R. J. Johnson, J. Am. Chem. Soc., 1938, 60, 105-111.

32 N. Fujita, S. Shinkai and T. D. James, Chem. - An Asian J., 2008, 3, 1076-1091.

33 R. R. Giri, H. Ozaki, T. Morigaki, S. Taniguchi and R. Takanami, Water Sci. Technol., 2011, 63, 276-282.

34 A. A. Thomas and S. E. Denmark, Science (80-. )., 2016, 352, 329-332.

35 A. A. Thomas, H. Wang, A. F. Zahrt and S. E. Denmark, J. Am. Chem. Soc., 2017, 139, 
3805-3821.

36 H. G. Kuivila, J. F. Reuwer Jr. and J. A. Mangravite, Can. J. Chem., 1963, 41, 30813090.

37 I. Omari, P. Randhawa, J. Randhawa, J. Yu and J. S. Mcindoe, J. Am. Soc. Mass Spectrom., 2019, 30, 1750-1757.

38 B. P. Carrow and J. F. Hartwig, J. Am. Chem. Soc., 2011, 133, 2116-2119. 